\title{
Motivasi Dan Komitimen Organisasi Terhadap Disiplin Kerja Pagawai Aparat Sipil Negara (ASN)
}

\author{
${ }^{1}$ Muh. Yusuf Qamaruddin, ${ }^{2}$ M. Risal, ${ }^{3}$ Herna Sudarman \\ Universitas Muhammadiyah Palopo, Sulawesi Selatan, Indonesia \\ Email : ${ }^{1}$ myusuf@umpalopo.ac.id, ${ }^{2}$ mrisal@umpalopo.ac.id \\ henrasudarman@student.umpalopo.ac.id
}

(Diterima: Juli 2021; Direvisi: Juli 2021; Dipublikasikan: September 2021)

\begin{abstract}
ABSTRAK
Motivasi dan komitmen organisasi dikategorikan sebagai foaktor-faktor yang dapat mempengaruhi disiplin kerja. Sehingga Penelitian ini memiliki tujuan untuk mengetahui dan menganalisis pengaruh motivasi dan komitmen oraganisasi terhadap disiplin kerja pegawai pada Dinas Pariwisata dan Dinas Tenaga Kerja. berdasarkan temuan penelitian menggunaka SPSS 21 dengan jumlah responden sebanyak 79 orang maka hasil penelitian menunjukkan bahwa motivasi dan komitmen organisasi memiliki pengaruh yang signifikan terhadap disiplin kerja pegawai pada Dinas Pariwisata dan Dinas Tenaga Kerja baik secara parsial maupun secara simultan.
\end{abstract}

Kata Kunci: Motivasi, Komitmen Organisasi, Disiplin Kerja 


\section{PENDAHULUAN}

Manajemen sumber daya manusia sangat berperan penting untuk mengatur pengelolaan sumber daya manusia dan sumber daya perusahaan atau organisasi, agar dapat memberikan suatu hasil yang maksimal. Manajemen mempunyai arti yang sangat luas, dapat berarti proses, seni, ataupun ilmu. Dikatakan proses karena manajemen terdapat beberapa tahapan untuk mencapai tujuan yaitu perencanaan, pengorganisasian, pengarahan, dan pengawasan. Dikatakan seni karena manajemen suatu cara atau alat untuk seorang manajer dalam mencapai tujuan (Barsah, 2019). Faktor sumber daya khususnya manusia sangat penting bagi keberhasilan organisasi mencapai tujuannya. Manusia yang sifatnya dinamis dapat dibentuk menjadi insan yang produktif yang dapat bersaing dengan kompetitorkompetitor yang ada. Produktifitas ini hanya dapat dibentuk dengan kedisiplinan yang dimiliki oleh seorang karyawan atau pegawai pada sebuah lembaga baik pemerintah atau swasta. Disiplin kerja sendiri pada dasarnya dianggap sebagai kesadaran karyawan dalam menjalankan tugas dan tanggung jawabnya pada lembaga tempat dia bekerja.

Faktor manusia harus menjadi perhatian utama dalam pelaksanaan tata kelola sebuah instansi. Faktor manusia yang memiliki kedisiplinan erat kaitannya dengan motivasi kerja yang dimiliki. Motivasi sendiri dipandang sebagai hal yang mendasari seseorang dalam melekukan sesuatu (Fauzan, 2017). Sehingga dapat dikatakan bahwa motivasi sebagai salah satu faktor yang dapat mempengaruhi disiplin kerja pegawai.

Selanjutnya, faktor lain yang dapat mempengaruhi disiplin kerja adalah komitmen organisasi. Kedisiplinan tidak akan dapat di terapkan dan dimanipfestasikan dalam bentuk tindakan jika tidak di landasi dengan komitmen organisasi yang kuat (Damri, Marzolina, \& Haryetti, 2017). Komitmen organisasi sebagai bentuk tanggung jawab bagi pegawai dalam memahami, mematuhi, dan melaksanakan tugas yang diberikan oleh persahaan atau instansi.

Diskusi pra penelitian yang dilakukan sementara menyimpulkan bahwa dua faktor ini yaitu motivasi dan komitmen organisasi membawa pengaruh pada disiplin kerja. Penelitian yang dilakukan oleh (Septiani, Sunuharyo, \& Prasetya, 2016) mengatakan bahwa komitmen organisasi berpengaruh segnifikan terhadap disiplin kerja. Penelitian Susanty \& Baskoro (2013) mengatakan motivasi memeiliki pengaruh yang signifikan pada displin kerja. Berdasarkan penelitian tersebut, maka penelitian ini dilakukan dengan maksud untuk mengonfirmasi temuan penenelitian sebelumnya apakah sesuai jika penelitian ini dilaksanakan pada Dinas Pariwisata dan Dinas Tenaga Kerja.

\section{TINJAUAN PUSTAKA}

\section{Motivasi}

Motivasi merupakan gerakan secara sadar dalam mealukan sesuatu (Zahari, 2015). Motivasi juga disebut sebagai serangkaian prilaku atas sikap dan nilai yang menjadi pendorong 
sesorang melakukan tindakan dengan maksud mencapai sebuah tujuan (Saputra, 2016). Sehingga disimpulkan bahwa perlu adanya dukungan motivasi bagi keryawan agar dapat membawa dampak positif bagi perusahaan.

Dalam mengukur tingkat motivasi pada keryawan maka setidaknya diperlukan beberapa indikator diantaranya arah perilaku, tingkat usaha, dan tingkat kegigihan (Sutanto, 2018).

\section{Komitmen Organisasi}

Komitmen organisasi adalah bentuk konstruk dari hubungan anggota oganisasi (Mujib \& Indartono, 2015). Tania et al. (2020) bahwa komitmen organisasi adalah perasaan dengan tanggung jawab yang sangat besar yang dimiliki setiap individu dalam sebuah organisasi demi tercapainya sebuah tujuan. Komitmen organisasi juga dianggap sebagai sikap suka rela dalam memegang tegh visi dan misi organisasi dan secara suka rela mengerahkan seluruh kemampuan demi tercapainya tujuan organisasi (Dewi \& Suratman, 2014).

Dalam mengukur tingkat komitmen organsisi pada keryawan maka setidaknya diperlukan beberapa indikator diantaranya komitmen efektif, komitmen berkelanjutan dan komitmen normatif (Sudarmanto, 2009).

\section{Disiplin Kerja}

Disiplin kerja adalah gambaran sikap seorang pegawai dalam menjalani kesehariannya pada sebuah instansi tempat ia bekerja (Dewi \& Suratman, 2014).
Hermaya \& Yuniawan 2018) menjelaskan bahwa disiplin kerja sebagai cara seorang karyawan dalam berperilaku sehingga dengan hal itu dapat merubah kebiasaan-kebiasaan menyimpang menjadi kebiasaan yang menaati norma dan aturan perusahaan. Lebih jauh disebutkan bahwa disiplin kerja rangkaian tingkah laku dan perbuatan seseorang yang selalu berada dalam koridor yang sesuai dengan aturan dan norma baik secara tertulis maupun tidak tertulis (Kusumayadi \& Ali, 2019).

Dalam mengukur tingkat disiplin kerja pada keryawan maka setidaknya diperlukan beberapa indikator diantaranya tujuan dan kemampuan; teladan pemimpin; balas jasa; keadilan; ketegasan pemimpin; hubungan kemanusiaan (Hasibuan, 2015).

\section{Hipotesis Penelitian}

$\mathrm{H} 1$ : diduga bahwa motivasi berpengaruh signifikan terhadap disiplin kerja secara persial pada Dinas Pariwisata dan Dinas Tenaga Kerja

H2: diduga bahwa komitmen organisasi berpengaruh signifikan terhadap disiplin kerja secara parsial pada Dinas Pariwisata dan Dinas Tenaga Kerja

H3: diduga bahwa motivasi dan komitmen organisasi berpengaruh signifikan terhadap disiplin kerja secara simultan pada Dinas Pariwisata dan Dinas Tenaga Kerja. 


\section{METODE PENELITIAN}

\section{Populasi}

Populasi adalah tingkat wilayah generalisasi yang terdiri atas objek atau subjek yang mempunyai kualitas dan karateristik tertentu yang diterapkan oleh peneliti untuk dipelajari dan ditarik kesimpulan. Jadi populasi bukan hanya orang, tetapi juga objek dan benda alam lainnya (Sugiyono, 2017). Populasi dalam penelitian adalah seluruh pegawai yang terdaftar pada Dinas Pariwisata dan Dinas Tenaga Kerja Kota Palopo yang berjumlah 79 pegawai.

\section{Sampel}

Sampel dalam penelitian ini adalah keseluruhan populasi yang dijadikan sampel sebanyak 79 pegawai.

\section{Jenis Penelitian}

Penelitian ini bersifat deskriptif kuantitatif yang bertujuan menggambarkan data yang terkumpul dalam bentuk angka dengan menggunakan statistik.

\section{Metode Analisis Data}

Untuk melihat hasil dari penelitian ini maka digunakan beberapa tahapan pengujian dengan aplikasi SPSS 21. Tahapan pengujian terdiri dari uji validitas, uji reliabilitas, uji f, uji koefisien determinasi $\left(\mathrm{R}^{2}\right)$ dan uji koefisien regresi berganda serta uji t.

\section{HASIL PENELITIAN}

\section{Uji Validitas}

Sebelum menghasilkan model regresi berganda, perlu dilakukan uji pendahuluan terlebih dahulu melalui uji validitas dan uji reliabilitas serta melakukan pengujian asumsi klasik. Uji validitas data diperoleh dari hasil penyebaran kuesioner terhadap 79 reponden dengan tingkat signifikansi sebesar 5\%. Tingkat validitas dilakukan dengan membandingkan nilai $r$ hitung dan $\mathrm{r}$ tabel (0.195). jika nilai $r$ hitung $>$ $r$ tabel maka angket penelitian dinyatakan valid

Tabel 1. Hasil Uji Validitas

\begin{tabular}{llll}
\hline \multicolumn{1}{c}{ Variabel } & & Faktor loading & Kesimpulan \\
\hline Motivasi & MTI_1 & 0,528 & Valid \\
& MTI_2 & 0,372 & Valid \\
& MTI_3 & 0,378 & Valid \\
Komitmen Organisasi & MTI_4 & 0,559 & Valid \\
& KO_1 & 0,223 & Valid \\
& KO_2 & 0,443 & Valid \\
Disiplin Kerja & KO_3 & 0,526 & Valid \\
& KO_4 & 0,349 & Valid \\
& DK_1 & 0,460 & Valid \\
& DK_2 & 0,264 & Valid \\
& DK_3 & 0,304 & Valid \\
& DK_4 & 0,264 & Valid \\
& DK_5 & 0,224 & Valid \\
\hline
\end{tabular}

Sumber : Data Primer Diolah, 2021 


\section{Uji Reliabiltas}

Pada penelitian ini digunakan reliabilitas dengan model Alpha Cronbach.

Tabel 2. Hasil Uji Reliabilitas

\begin{tabular}{lcl}
\hline \multicolumn{1}{c}{ Variabel } & $\begin{array}{c}\text { Cronbach's } \\
\text { Alpha }\end{array}$ & Kesimpulan \\
\hline Motivasi & 7,177 & Reliabel \\
Komitmen & 8,921 & Reliabel \\
$\begin{array}{l}\text { Organisasi } \\
\text { Disiplin }\end{array}$ & 7,380 & Reliabel \\
Kerja & & \\
\hline
\end{tabular}

Sumber : Data Primer Diolah, 2021

\section{Uji Model (F)}

Instrumen dinyatakan tidak reliabel jika nilai reliabilitas yang diperoleh tidak mencapai 0,6 (Jogiyanto, 2010). Hasil uji reliabilitas yang disajikan pada tabel di atas menunjukkan bahwa masing-masing nilai koefisien reliabilitas lebih besar dari 0,6 sehingga instrumen yang digunakan dinyatakan reiabel. Tabel 3. Uji f

\begin{tabular}{|c|c|c|c|c|c|}
\hline Model & $\begin{array}{l}\text { Sum } \\
\text { of } \\
\text { Squar } \\
\text { es }\end{array}$ & $\begin{array}{l}d \\
f\end{array}$ & $\begin{array}{c}\text { Mean } \\
\text { Squar } \\
\text { e }\end{array}$ & $\mathrm{F}$ & Sig. \\
\hline $\begin{array}{l}\text { Regressi } \\
\text { on }\end{array}$ & 2,154 & 2 & 1,077 & $\begin{array}{c}4,79 \\
8\end{array}$ & $\underset{\mathrm{b}}{, 011}$ \\
\hline 1 Residual & $\begin{array}{c}17,06 \\
1\end{array}$ & 7 & 224 & & \\
\hline Total & $\begin{array}{c}19,21 \\
5\end{array}$ & 7 & & & \\
\hline
\end{tabular}

Sumber: data diolah, 2021

Seperti yang diketahui bahwa fungsi dari uji $\mathrm{f}$ atau uji simultan adalah untuk melihat pengaruh seluruh variabel independen terhadap variabel dependen. Dalam hal ini seluruh varibel independen pada penelitian ini yaitu motivasi dan komitmen organisasi memiliki pengaruh yang signifikan terhadap disiplin kerja pegawai dengan nilai singnifikansi sebesar 0,011 atau berada dibawah tingkat alpha yaitu 0,05 .

\section{Uji Koefisien Determinasi $\left(\mathbf{R}^{\mathbf{2}}\right)$}

Koefisien determinasi bertujuan untuk menunjukkan besarnya derajat hubungan antara motivasi dan komitmen organisasi terhadap disiplin kerja.

Tabel 4. Hasil Uji Koefisien Determinasi Model R R Adjusted Std. Square R Square Error of the

Estimate

$\begin{array}{llll}1 & , 335^{\mathrm{a}}, 112 \quad 089 & , 474\end{array}$

Nilai $\mathrm{R}^{2}$ pada hasil uji koefisien determinasi menunjukkan hasil sebesar 0,112 atau $11,2 \%$. Dari nilai itu dapat dijelaskan bahwa besaran kontibusi yang dapat disumbang oleh variabel motivasi dan komitmen organisais terhadap disiplin kerja pada dinas Dinas Pariwisata dan Dinas Tenaga Kerja Kota Palopo adalah sebesar 11,2\%. Hal ini mengindikasikan bahwa ada variabel lain diluar variabel yang ada dalam penelitian ini yang dapat mempengaruhi disiplin kerja pegawai akan tetapi tidak dimasukkan dalam penelitian ini.

Tabel 5. Hasil Uji Koefisien Regresi Model Unstandardized

\begin{tabular}{llcc} 
& & \multicolumn{2}{c}{ Coefficients } \\
\cline { 3 - 4 } & & B & $\begin{array}{c}\text { Std. } \\
\text { Error }\end{array}$ \\
\hline \multirow{2}{n}{1} & (Constant) & 23,976 & 2,017 \\
& Motivasi &, 195 &, 081 \\
& Komitmen_Organisasi &, 175 &, 078 \\
\hline
\end{tabular}

Sumber: data diolah, 2021

Tabel 5 diatas menunjukkan hasil dari koefisien regersi dengan menggunakan software SPSS 21. Dimana persamaan yang dihasilkan dapat dituliskan dengan model seperti berikut:

$$
\mathrm{Y}=23,976+0,195 \mathrm{M}+
$$

$0,175 \mathrm{KO}$ 
Dengan model
diatas maka dapat $\begin{array}{r}\text { dijelaskan } \\ \text { beberapa yang }\end{array}$ persamaan tersebut dimana: konstanta dengan nilai sebesar 23,976 ditafsirkan bahwa variabel kedua variabel independen yakni motivasi dan komitmen organisasi tidak mempengaruhi disiplin kerja sebesar 23,976. Jika setiap varibel independen yang dimasukkan dalam penelitian diasusikan memiliki nilia sama dengan 0 maka variabel dependen yaitu disiplin kerja akan tetep pada nilai konstanta 23,976. Berdasarkan hal tersebut dapat disimpulkan bahwa ada faktor lain atau ada variabel lain yang dapat mempengaruhi disiplin kerja pada Dinas Pariwisata dan Diana Tenaga Kerja Kota Palopo selain variabel motivasi dan komitmen organisasi.

Untuk variabel motivasi dengan nilai sebesar 0,195. Sehingga hal ini dikatakan bahwa varibel motivasi memiliki pengaruh positif terdap disiplin kerja. Artinya akan ada peningkatan dalam hal disiplin kerja sebesar 0,195 jika ada peningkatan atau perbaikan pada variabel motivasi dengan asumsi komitmen organisasi nilainya konstan.

Untuk variabel komitmen organisasi dengan nilai sebesar 0,175. Sehingga hal ini dikatakan bahwa varibel komitmen organisasi memiliki pengaruh positif terdap disiplin kerja. Artinya akan ada peningkatan dalam hal disiplin kerja sebesar 0,175 jika ada peningkatan atau perbaikan pada variabel komitmen organisasi dengan asumsi variabel motivasi nilainya konstan.
Tabel 6. Uji t

\begin{tabular}{llcc}
\hline $\begin{array}{l}\text { Mod } \\
\text { el }\end{array}$ & & t & $\begin{array}{c}\text { Sig } \\
\text {. }\end{array}$ \\
\hline & & 11,88 &, 00 \\
& (Constant) & 7 & 0 \\
1 & Motivasi & 2,400 &, 01 \\
& Komitmen_Organi & 2,239 & 9 \\
& sasi & &, 02 \\
& & & 8 \\
\hline
\end{tabular}

Sumber: data diolah, 2021

Pada tabel 6 di atas menunjukkan nilai dari uji $\mathrm{t}$ pada masing-masing variabel dimana semuanya memiliki nilai yang singnifikan atau berada pada tingkat alpha yaitu $5 \%$.

Variabel motivasi dengan tingkat signifikan sebesar 0,019 dapat diartikan bahwa variabel ini secara signifikan mempengaruhi disiplin kerja. Dengan kesimpulan akhir bahwa disiplin kerja akan mengalami perbaikan dan peningkatan jika motivasi yang dimiliki setiap pegawai yang ada pada Dinas Parowisata dan Dinas Tenaga Kerja Kota Palopo ditingkatkan secara berkala.

Variabel komitmen organisasi dengan tingkat signifikan sebesar 0,028 dapat diartikan bahwa variabel ini secara signifikan mempengaruhi disiplin kerja. Dengan kesimpulan akhir bahwa disiplin kerja akan mengalami perbaikan dan peningkatan jika komitmen organisasi secara matang dapat dipahami dan diterapkan oleh masing-masing pegawai yang ada pada dinas Dinas Pariwisata dan Dinas Tenaga Kerja Kota Palopo.

\section{PEMBAHASAN}

\section{Motivasi Berpengaruh Pada Disiplin Kerja Pegawai}

Berdasrkan dari hasil penelitian ini yang menyatakan bahwa motivasi berpengaruh positif dan signifikan terhadap 
disiplin kerja pegawai pada Dinas Pariwisata dan Diana Tenaga Kerja Kota Palopo dimana penelitian ini sesuai dengan penelitian Oktaria \& Nugraheni (2017) yang meneliti tentang "Pengaruh Lingkungan Kerja, Kepuasan Kompensasi dan Motivasi Kerja Pegawai pada PDAM Tirta Moedal Kota Semarang" menyatakan bahwa lingkungan kerja berpengaruh positif dan signifikan terhadap disiplin kerja, kepuasan kompensasi berpengaruh positif dan signifikan terhadap disiplin kerja dan begitu juga dengan motivasi yang berpengaruh positif dan signifikan terhadap disiplin kerja pegawai.

2. Komitmen

Organisasi

Berpengaruh Pada Disiplin Kerja Pegawai

Komitmen organisasi sangat erat kaitannya dengan kedisiplinan kerja, segabaimana diungkapkan Harnoto (2006) bahwa jika seseorang tidak memiliki komitmen organisasi yang tinggi maka akan bersikap acuh dan merasa tidak memiliki tnggung jawab atas apapun yang berkkaitan dengan oraganisasi tempat ia berada. Hasil dari penelitian ini menunjukkan bahwa komitmen organisasi berpengaruh positif dan signifikan terhadap disiplin kerja pegawai Dinas Pariwisata dan Diana Tenaga Kerja Kota Palopo dengan demikian membuktikan bahwa setiap ada penigkatan komitmen organisasi maka akan berpengaruh untuk meningkatkan disiplin kerja. Penelitian ini sejalan dengan penelitian yang dilakukan Singal et al. (2018) dengan penelitian "Analisis Pengaruh Iklim Organisasi Dan Komitmen Organisasi Terhadap Disiplin Kerja Pegawai (Studi Di Bank Mendiri Area Manado)" menyatakan bahwa iklim organisasi berpengaruh signifikan terhadap disilin kerja, begitupun dengan komitmen organisasi juga berpengaruh signifikan pada disiplin kerja pegawai pada Bank Mandiri area Manado dari hasil ini kedua variabel berpengaruh signifikan secara parsial dan juga simultan.

\section{PENUTUP}

Kesimpulan

Penelitian ini bertujuan untuk mengetahui dan menganalisis pengaruh variabel motivasi dan komitmen organisasi terhadap disiplin kerja pada Dinas Pariwisata dan Dinas Tenaga Kerja Kota Palopo berdasarkan hasil penelitian ini ditarik kesimpulan bahwa setiap variabel independen dalam penelitian ini berpengaruh signifikan secara parsial dan simultan dengan tingkat signifikansi untuk variabel motivasi 0,019 dan komitmen organisasi dengan nilai signifikansi 0,028 . Secara simultan dengan nilai signifansi 0,011 . Selain itu penelitian tersebut juga menunjukkan bahwa kedua variabel inidependen sangat kecil pengaruhnya terhadap disiplin kerja yaitu sebesar $11,2 \%$.

\section{Saran}

Hasil dari temuan penelitian dan kesimpulan yang telah di jelaskan, maka disampaikan beberapa saran untuk menjadi acuan dalam proses perbaikan tingkat kedisiplin pegawai pada Dinas Pariwisata dan 
Dinas Tenaga Kerja Kota Palopo sebagai berikut:

1. Bahwa dalam upaya peningkatan disiplin kerja pegawai perlu adanya terobosan baru dalam proses pengelolaan sistem tata kelola pemerintahan dalam meningkatkan motivasi pegawai, misalnya memberikan penghargaan bagi pegawai yang memiliki kedisplinan tinggi dalam bekerja. Dalam hal menigkatkan motivasi perlu mencoba hal-hal baru misalnya pimpinan melakukan outbound gathering bersama seluruh pegawai, hal ini juga sebagai upaya menigkatkan kebersamaan diantara pegawai agar saling memotivasi dalam berbagi hal sehingga dapat menigkatkan displin kerja kedepannya.

2. Peningkatan komitmen organisasi aka berdampak pada disiplin kerja sehingga dalam hal menigkatkan komitmen organisasi perlu dilakukan peltihan kepada pegawai dan juga perlu memberi jaminan kepada pagawai bahwa setiap keberhasilan yang dilakukan dalam sebuah pekerjaan akan mendapatkan penghargaan, sehingga hal ini akan memacu pegawai dalam meningkatkan kedisiplinan kerjanya.

\section{DAFTAR PUSTAKA}

Barsah, A. (2019). Pengaruh Motivasi Dan Disiplin Terhadap Kinerja Pegawai Pada Dinas Kependudukan Dan Pencatatan Sipil Kota Tangerang. Jenius, 3(1), 1-15.

Damri, Z., Marzolina, M., \& Haryetti, H. (2017). Pengaruh Komitmen Organisasi, Kepuasan Kerja, dan Kepemimpinan terhadap Disiplin Kerja Pegawai Biro Administrasi Pemerintahan Umum Provinsi Riau. Jurnal Online Mahasiswa Fakultas Ekonomi Universitas Riau, 4(1), 656-666.

Dewi, Y. R., \& Suratman, B. (2014). Komunikasi Organisasi dan Komitmen Organisasi Kaitannya Tterhadap Disiplin Kkerja Pegawai Pada Kantor Imigrasi Kelas II Blitar, (2), 116.

Fauzan, M. (2017). Pengaruh Kepemimpinan Dan Motivasi Kerja Terhadap Disiplin Kerja Pegawai (Sebuah Kajian Ekonomi Sumber Daya Manusia Studi Kasus Pada Pt. Bank Muamalat Indonesia Cabang Pematangsiantar). Jurnal Ekonomi \& Studi Pembangunan, 18(1). https://doi.org/10.18196/jesp.1 8.1.3781

Hermaya, Z. M., \& Yuniawan, A. (2018). Analisis Pengaruh Iklimorganisasi, Komunikasi Organisasi Dan Komitmen Organisasi Terhadap Disiplin Kerja (Studi Pada Karyawan Divisi Operasional PT. Plasa Simpanglima Semarang). Diponegoro Journal of Management, 7(1), 1-15.

Kusumayadi, F., \& Ali, M. (2019).

Iklim Organisasi Dan Komitmen Organisasi Terhadap Kedisiplinan Kerja Pegawai Pada Kantor Sekretariat Dprd Kabupaten Bima. Jmm Unram - Master of Management Journal, 8(4), 503-513.

https://doi.org/10.29303/jmm.v 
$8 \mathrm{i} 4.473$

Mujib, M., \& Indartono, S. (2015). Pengaruh Lingkungan Kerja Dan Komitmen Terhadap Disiplin Kerja (Studi Pada Pegawai Badan Kepegawaian Daerah Diy). Prosiding Seminar Nasional, 51-63.

Oktaria, R. A., \& Nugraheni, R. (2017). Pengaruh Lingkungan Kerja,Kepuasan Kompensasi, dan Motivasi Kerja Terhadap Disiplin Kerja Pegawai Pada PDAM Tirta Moedal Kota Semarang. Diponegoro Journal of Management, 6(Nomor 3), $1-10$.

Saputra, T. (2016). Pengaruh Motivasi Kerja Terhadap Disiplin Kerja Pegawai Pada Dinas Pemuda Dan Olahraga Provinsi Riau.

Septiani, M., Sunuharyo, B., \& Prasetya, A. (2016). Pengaruh Komitmen Organisasional Terhadap Disiplin Kerja dan Kinerja Karyawan (Studi Pada Karyawan AJB Bumiputera 1912 Cabang Celaket Malang). Jurnal Administrasi Bisnis S1 Universitas Brawijaya, 40(2), 98-105.

Singal, D. L., Dotulong, L. O. H., Manajemen, J., Sam, U., \& Manado, R. (2018). Analisis Pengaruh Iklim Organisasi Dan Komitmen Organisasi Terhadap Disiplin Kerja Pegawai (Studi Di Bank Mandiri Area Manado). Jurnal EMBA: Jurnal Riset Ekonomi, Manajemen, Bisnis Dan Akuntansi, 6(4), 2678-2687. https://doi.org/10.35794/emba. v6i4.21049

Barsah, A. (2019). Pengaruh Motivasi
Dan Disiplin Terhadap Kinerja Pegawai Pada Dinas Kependudukan Dan Pencatatan Sipil Kota Tangerang. Jenius, 3(1), 1-15.

Damri, Z., Marzolina, M., \& Haryetti, H. (2017). Pengaruh Komitmen Organisasi, Kepuasan Kerja, dan Kepemimpinan terhadap Disiplin Kerja Pegawai Biro Administrasi Pemerintahan Umum Provinsi Riau. Jurnal Online Mahasiswa Fakultas Ekonomi Universitas Riau, 4(1), 656-666.

Dewi, Y. R., \& Suratman, B. (2014). Komunikasi Organisasi dan Komitmen Organisasi Kaitannya Tterhadap Disiplin Kkerja Pegawai Pada Kantor Imigrasi Kelas II Blitar, (2), 116.

Fauzan, M. (2017). Pengaruh Kepemimpinan Dan Motivasi Kerja Terhadap Disiplin Kerja Pegawai (Sebuah Kajian Ekonomi Sumber Daya Manusia Studi Kasus Pada Pt. Bank Muamalat Indonesia Cabang Pematangsiantar). Jurnal Ekonomi \& Studi Pembangunan, $\quad$ 18(1). https://doi.org/10.18196/jesp.1 8.1.3781

Hasibuan, M. (2015). Manajemen Sumber Daya Manusia. Jakarta: PT. Bumi Aksara.

Hermaya, Z. M., \& Yuniawan, A. (2018). Analisis Pengaruh Iklimorganisasi, Komunikasi Organisasi Dan Komitmen Organisasi Terhadap Disiplin Kerja (Studi Pada Karyawan Divisi Operasional PT. Plasa Simpanglima Semarang). Diponegoro Journal Of 
Management, 7(1), 1-15.

Kusumayadi, F., \& Ali, M. (2019). Iklim Organisasi Dan Komitmen Organisasi Terhadap Kedisiplinan Kerja Pegawai Pada Kantor Sekretariat Dprd Kabupaten Bima. Jmm Unram - Master of Management Journal, 8(4), 503-513.

https://doi.org/10.29303/jmm.v $8 \mathrm{i} 4.473$

Mujib, M., \& Indartono, S. (2015). Pengaruh Lingkungan Kerja Dan Komitmen Terhadap Disiplin Kerja (Studi Pada Pegawai Badan Kepegawaian Daerah Diy). Prosiding Seminar Nasional, 51-63.

Oktaria, R. A., \& Nugraheni, R. (2017). Pengaruh Lingkungan Kerja,Kepuasan Kompensasi, dan Motivasi Kerja Terhadap Disiplin Kerja Pegawai Pada PDAM Tirta Moedal Kota Semarang. Diponegoro Journal of Management, 6(Nomor 3), $1-10$.

Saputra, T. (2016). Pengaruh Motivasi Kerja Terhadap Disiplin Kerja Pegawai Pada Dinas Pemuda Dan Olahraga Provinsi Riau.

Septiani, M., Sunuharyo, B., \& Prasetya, A. (2016). Pengaruh Komitmen Organisasional Terhadap Disiplin Kerja dan Kinerja Karyawan (Studi Pada Karyawan AJB Bumiputera 1912 Cabang Celaket Malang). Jurnal Administrasi Bisnis S1 Universitas Brawijaya, 40(2), 98-105.

Singal, D. L., Dotulong, L. O. H., Manajemen, J., Sam, U., \& Manado, R. (2018). Analisis
Pengaruh Iklim Organisasi Dan Komitmen Organisasi Terhadap Disiplin Kerja Pegawai (Studi Di Bank Mandiri Area Manado). Jurnal EMBA: Jurnal Riset Ekonomi, Manajemen, Bisnis Dan Akuntansi, 6(4), 2678-2687. https://doi.org/10.35794/emba. v6i4.21049

Sudarmanto. (2009). Kinerja dan Pengembangan Kompetensi Sumber Daya Manusia. Jakarta: Pustaka Belajar.

Susanty, A., \& Baskoro, S. W. (2013). Pengaruh Motivasi Kerja Dan Gaya Kepemimpinan Terhadap Disiplin Kerja Serta Dampaknya Pada Kinerja Karyawan (Studi Kasus Pada Pt. Pln (Persero) Apd Semarang).J J@Ti Undip: Jurnal Teknik Industri, 7(2), 77-84.

https://doi.org/10.12777/jati.7. 2.77-84

Sutanto, I. T. dan E. M. (2018). Pengaruh Kepuasan Pada Kompensasi, Motivasi Kerja, dan Komitmen Organisasional Terhadap Kedisplinan Kerja Sopir Tetap PT. Sumber Karya, 6(2).

Tania, M., Tarigan, I., \& Syawaluddin. (2020). Kerja Terhadap Disiplin Kerja Karyawan Pt . Trans Sumatera Agung Medan. Jurnal Bisnis Kolega, 6(1), 57-70.

Zahari, M. (2015). Pengaruh Motivasi Terhadap Disiplin Kerja Pegawai Pada Dinas Perindutrian dan Perdagangan Provinsi Jambi. Jurnal Ilmiah Ekonomi Dan Bisnis, 6(1), 4757. 